\title{
ESTRATÉGIAS SOCIAIS CRIATIVAS EM BARCELONA. O CASO DO WALDEN-7
}

\author{
ISABEL ANDRÉ ${ }^{1}$ \\ MURIEL RousSELLE ${ }^{2}$
}

\begin{abstract}
Resumo - Sendo Barcelona uma metrópole reconhecida como meio inovador, reflectimos neste artigo sobre as condições e as oportunidades que oferece para a inovação social, ou seja, para o desenvolvimento de estratégias criativas que apontem novas soluções para problemas sociais sem resposta adequada. Centramos esta reflexão na produção do espaço urbano residencial e focamos, em particular, o caso do Walden-7 em Sant Just Desvern, Área Metropolitana de Barcelona, uma experiência com 4 décadas, frequentemente referida como uma "utopia urbana realizada". Tratase de uma intervenção muito precoce de regeneração urbana, onde o desenho dos espaços colectivos, a concepção de novas relações de vizinhança e organização interna dos apartamentos deixaram traços marcantes de inovação social. Neste artigo, pretende-se, sobretudo, equacionar o papel da adversidade como impulso socialmente criativo, bem como a temporalidade e o percurso das inovações sociais.
\end{abstract}

Palavras-chave: Inovação social, meio socialmente criativo, utopia urbana, Walden-7, Barcelona.

\begin{abstract}
Creative social strategies in Barcelona. The Walden-7 case. The metropolis of Barcelona is widely recognised as an innovating milieu. This article focuses on the conditions and opportunities the city offers for social innovation, that is to say the development of creative strategies pointing at new solutions for social problems left without adequate answers. We focus our study upon the development of residential urban space and we take a special interest in the Walden-7 case, located at Sant Just Desvern, Metropolitan Area of Barcelona - four decades of experience frequently referred to as an "accomplished urban utopia". The Walden-7 is a very early intervention of urban regeneration where the design of collective space, the conception of new neighbourhood relationships and the inside organisation of the apartments have left striking marks of social innovation. This article highlights the role played by adversity as a socially creative impulse alongside the temporality and the course of social innovations.
\end{abstract}

Recebido: 21/07/2010. Aceite: 26/11/2010.

1 Centro de Estudos Geográficos, Instituto de Geografia e Ordenamento do Território, Universidade de Lisboa E-mail: isabelandre@campus.ul.pt

2 Rede de Bibliotecas Públicas de Barcelona. E-mail: roussellerm@diba.cat 
Key words: Social innovation, socially creative milieu, urban utopias, Walden7, Barcelona.

Résumé - Stratégies Sociales CRÉATIVES À BARCELONE. Le CAS DU WALDEN-7. Barcelone étant une métropole reconnue comme milieu innovateur, nous tâchons ici de réfléchir sur les conditions et les opportunités qu'elle offre quant à l'innovation sociale, c'est-à-dire quant au développement de stratégies créatives tendant vers de nouvelles solutions face à des problèmes sociaux demeurés sans réponse adéquate. Nous centrons cette réflexion autour de la production de l'espace urbain résidentiel et nous nous intéressons en particulier au cas du Walden-7 à Sant Just Desvern, Zone Métropolitaine de Barcelone, une expérience sur bientôt 4 décennies fréquemment citée comme exemple d'utopie urbaine réalisée. Il s'agit d'une intervention très précoce de régénération urbaine, où la conception des espaces collectifs, celle de nouveaux rapports entre voisins et l'organisation interne des appartements ont laissé des traces marquantes d'innovation sociale. Dans cet article, nous visons principalement à souligner le rôle de l'adversité comme élan socialement créatif au même titre que la temporalité et le cours des innovations sociales.

Mots-clés: Innovation sociale, milieu socialement créatif, utopie urbaine, Walden-7, Barcelone.

\section{INTRODUÇÃO}

Associada a grandes artistas e a empresas e empresários dinâmicos, Barcelona ocupa lugar de relevo no mapa da criatividade e da inovação. O desenvolvimento económico precoce como porto do Mediterrâneo, a industrialização fortemente ligada ao comércio exterior e os ideais nacionalistas contribuíram muito para essa imagem que o Mundo tem de Barcelona. As artes, a cultura e a economia são efectivamente actividades ricas e dinâmicas nesta metrópole. E no campo social? Será também Barcelona um meio socialmente criativo e inovador, que incentiva e provoca a mudança social no sentido de se tornar uma comunidade urbana mais justa, mais inclusiva e mais coesa?

É esta questão que desenvolvemos no artigo, focando a atenção num caso particular, mas ilustrativo. Com mais de 4 décadas de existência, o Walden-7, em Sant Just Desvern (Área Metropolitana de Barcelona), é o resultado de um projecto visionário, desenvolvido por um colectivo interdisciplinar (Taller d'Arquitectura), liderado por Ricardo Bofill. Trata-se de uma interessante experiência, em que as configurações espaciais parecem ter tido um impacto importante nas dinâmicas sociais de uma comunidade urbana, constituída actualmente por cerca de 1000 pessoas. 


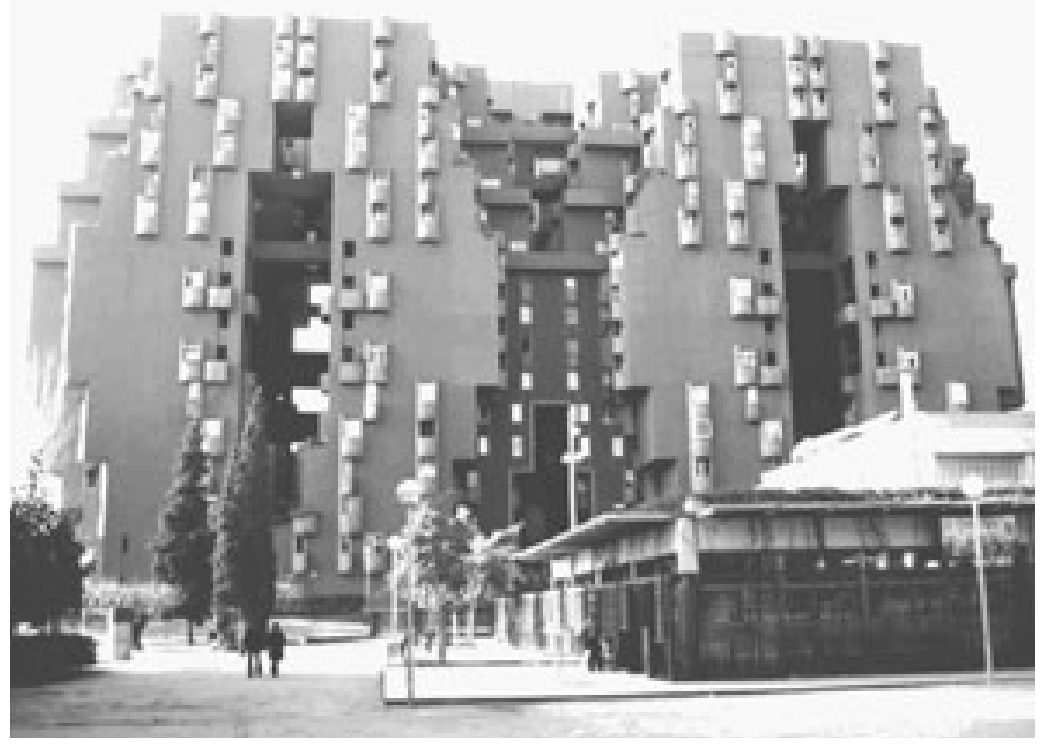

Fig. 1 - Walden-7, Sant Just Desvern, em 2010.

Fig. 1 - Walden-7, Sant Just Desvern, in 2010.

O Walden-7 traduz uma visão de cidade particularmente avançada para a sua época, associando experiências arquitectónicas e sociais, ambas equacionadas de modo muito inovador, em ruptura evidente com as perspectivas dominantes no final dos anos 60 . Nos pontos seguintes, apresentamos as linhas mestras do projecto e discutimos o seu significado, evolução e impactos sociais.

\section{ESTRATÉGIAS SOCIAIS CRIATIVAS}

As estratégias sociais criativas (ESC) são novas respostas da sociedade, ou de comunidades específicas, para problemas que o Estado ou o mercado não resolvem adequada ou satisfatoriamente. Assim entendidas, são estratégias capazes de gerar inovação social, na medida em que apontam para novas soluções, visam a coesão social e reconfiguram as relações sociais (relações de trabalho, de género, inter-étnicas, inter-geracionais, etc.).

$\mathrm{Na}$ realidade, as ESC transformam-se em inovação social se forem suficientemente reconhecidas e adoptadas.

Na sua essência, as ESC expressam sempre uma vontade de mudança que pode assumir contornos instrumentais e pragmáticos, ou estar ancorada em visões ideologicamente definidas. No entanto, mesmo nos casos em que estas estratégias visam objectivos muito concretos e particulares, não deixa de haver uma inspi- 
ração, uma utopia que funciona como pilar e como alavanca da mudança e da inovação social (Defourny e Develtere, 1999; Martinelli et al., 2003; Moulaert e Ailenei, 2005; Klein e Harrisson, 2007). Na Europa, as ideias corporativas pré-modernas, a filantropia burguesa do séc. XIX, a teoria social católica, o anarquismo, o socialismo, a social-democracia ou os movimentos mais recentes, plurais e alternativos, configuraram, de modo mais ou menos directo e mais ou menos explícito, os rumos de mudança da sociedade e os caminhos a trilhar pelas comunidades nacionais, regionais ou locais. As visões da cidade que se foram traduzindo nas políticas e nos planos urbanos, transmitem muito claramente essas visões ou a sua combinação.

Por outro lado, os vários Welfare Regimes (Esping-Anderson, 1990) que coexistem no espaço europeu modelam a interpretação e a aplicação das utopias sociais, fazendo-as adaptar a contextos específicos.

\section{Quem são os agentes que definem e desenvolvem as ESC?}

São diversos. Revelam, contudo, uma intenção comum de desafiar a ordem estabelecida. Na maioria dos casos, os principais protagonistas são os agentes mais vulneráveis, aqueles que precisam de uma resposta adequada e urgente para escapar ao risco de exclusão social. A História revela, no entanto, que muitas personagens das elites desempenham também esse papel de estrategas da mudança social. Não se tratará apenas, como os marxistas defendem, de uma opção de classe, mas também de uma 'incomodidade' ideológica, de um inconformismo que se revela, por exemplo, com bastante frequência, através das artes ou da arquitectura.

\section{Em que condições e contextos se configuram as ESC?}

Numa primeira leitura, as ESC parecem desencadear-se sobretudo por via da ameaça de exclusão social. As tensões inerentes à privação, à desigualdade e à consequente fragmentação das sociedades ou das comunidades surgem como fontes privilegiadas de criatividade social. Esta ideia leva alguns actores a defenderem que a criatividade e a inovação social estão intimamente ligadas ao conflito (Carnelave, 2008).

Todavia, outros desafios podem estar na génese de ESC. Para além das ameaças, que obrigam a respostas adequadas e eficazes, as oportunidades e os recursos são também geradores de criatividade social. A título de exemplo, uma escola que promova a intervenção, o debate e a criação e que encare o erro como forma de aprendizagem 'produz' certamente pessoas inquietas e exigentes relativamente à sociedade em que vivem, ou seja, pessoas socialmente criativas.

"Creativity drives innovation and evolution, providing original ideas and options, but it is also a reaction to the challenges of life. It sometimes helps when 
solving problems, but also sometimes allows problems to be avoided. It is both reactive and proactive" (Runco, 2004: 679).

\section{Quais os meios favoráveis às ESC?}

Diversos autores que exploraram esta questão (Gertler 2004; Tremblay et al., 2005; André e Abreu 2006 e 2009; Moulaert et al., 2009) sugerem que os meios socialmente criativos são aqueles que permitem a mudança, sem se fragmentarem e mantendo, ou reconstruindo, a sua identidade. Os meios socialmente criativos apresentam-se, assim, como territórios dinâmicos que combinam quatro condições: diversidade sócio-cultural, tolerância, participação cívica e capital relacional.

A diversidade potencia a interacção e o contacto com o novo no sentido da alteridade - novos-outros produtos, novos-outros saberes, novos-outros valores. A tolerância é uma condição necessária ao risco, sempre associado à criação e à inovação (como no trapézio, o risco implica uma rede). Um meio não pode ser criativo se penalizar os eventuais insucessos de uma iniciativa arriscada, ou seja, se for demasiado hierarquizado, normativo ou rígido. A participação cívica comporta a possibilidade e a capacidade de julgar e decidir, através do acesso à informação e ao conhecimento necessários à identificação de respostas novas e adequadas. O capital relacional diz respeito à interacção que advém quer dos laços de proximidade que accionam redes locais (de vizinhança, familiares, de amigos, etc.), quer do estabelecimento de pontes com o exterior. Não se trata apenas do capital social das elites, mas sobretudo da possibilidade e da capacidade, colectivamente apropriadas, de tornar os territórios mais coesos no seu interior e mais ligados ao resto do mundo.

\section{Existe uma escala apropriada para as ESC?}

Em geral, as ESC são normalmente associadas à escala local. É a este nível que as fragilidades e os défices sociais se revelam de uma forma mais evidente e que emerge mais claramente a necessidade de respostas de proximidade. Por outro lado, a relativa autonomia dos agentes locais e a sua 'amarração' à realidade quotidiana e concreta permite-lhes encarar a mudança social com mais facilidade, porque com menores implicações nas esferas de decisão económicas ou políticas.

Para além das razões invocadas, é também à escala local que a "consciência territorial" (Klein, 2005) - o sentido de pertença a uma comunidade - se configura, facilitando a participação, a tolerância e as relações de proximidade.

É, contudo, ilusório pensar que o nível local, nomeadamente as cidades ou mesmo comunidades mais pequenas, detêm o monopólio da criatividade e da inovação social. As políticas sociais, regionais ou nacionais, os planos e projectos de desenvolvimento territorial ou o dinamismo da economia nacional e 
internacional são fortes condicionalismos para as ESC. São as relações entre as diferentes escalas territoriais de regulação que promovem ou travam estas estratégias, embora elas se concretizem normalmente na micro-escala local.

\section{Finalmente: qual a temporalidade das ESC?}

Contrariamente ao que habitualmente se pensa, ou se faz pensar, a temporalidade das dinâmicas sociais é a das comunidades e não a dos indivíduos ou a dos ciclos políticos ou económicos. As utopias sociais que se concretizaram assumiram normalmente a necessidade do tempo longo, das diferentes fases necessárias à maturação de um projecto, desde a etapa inicial, rápida e intensa, em que se revelam, estruturam e ajustam ideias e perspectivas, até às etapas de experimentação e consolidação, necessariamente muito mais lentas.

\section{WALDEN-7: UMA UTOPIA REALIZADA?}

Como referimos na introdução, o Walden-7 é um caso especialmente interessante, com um percurso suficientemente longo e marcado por diferentes etapas, o que permite debater os vários aspectos das estratégias sociais criativas anteriormente enunciados. Com este objectivo, desenvolvemos uma ampla pesquisa documental, realizámos 9 entrevistas $^{3}$ e efectuámos um inquérito a residentes no Walden-7.

\section{Fundamentos da utopia}

Ricardo Bofill (Barcelona, 1939-) acabou os estudos de arquitectura em Genebra no ano de 1960. Da Suíça, trouxe ideias contestatárias que ecoavam as primeiras críticas ao urbanismo funcionalista personificado em Le Corbusier. O pensamento sobre a cidade desenvolvido por Henry Lefevre e muitos outros marxistas influenciaram fortemente Bofill. Era necessária e urgente uma cidade mais humanizada e menos determinada pelas leis do mercado imobiliário. Mas, as ideias de Ricardo Bofill sobre a construção do espaço urbano não vinham só dessa vanguarda europeia que começava a fazer-se ouvir. Vinham também do seu pai e da sua terra natal, a Catalunha. Emílio Bofill, também arquitecto, pertencia à burguesia catalã e partilhava com ela os ideais nacionalistas, mas ia mais além, criticando duramente o regime franquista, o que o aproximou da Esquerda Republicana e o impediu - por decisão dos poderes políticos fran-

3 Foram entrevistadas, em Fevereiro de 2010, as seguintes pessoas: Ana Bofill Levi (arquitecta, música, co-autora do projecto Walden-7 e aí residente desde a sua fundação), Cármen Mañá (responsável pelos serviços administrativos do Walden-7), Suzana Pera (responsável pela animação cultural do Walden-7) e 6 residentes no Walden-7 com idades compreendidas entre os 18 e os 65 anos. 
quistas - de assinar os seus projectos de arquitectura (Bofill, 1989; Bofill Levi, 2009; Anna Bofill Levi na entrevista realizada pelas autoras em Fevereiro de 2010).

Em 1960, Ricardo Bofill, acabado de chegar da Europa democrática, funda, em parceria com o seu pai e com um grupo alargado de colegas e amigos, o "Taller de Arquitectura". Era um grupo eclético e pluridisciplinar, constituído por arquitectos, engenheiros, urbanistas, sociólogos, escritores, músicos, cineastas e filósofos. Em conjunto, propunham-se repensar o espaço urbano e contestar a especulação imobiliária que já se fazia sentir em Barcelona, em especial no litoral, onde a pressão turística era cada vez mais intensa desde os anos 50 (Banyuls i Pérez, 2002).

"Le 'Taller de Arquitectura' s'est preparé à inventer des villes qui soient possibles, pleines de rêves réalisables et imparfaites" (Miralles 1975, cit. por Bourret, 1999: 25).

"Rétrospectivement, je ne sais comment nous parvenions à boucler nos fins de mois. Nous passions parfois beaucoup de temps, avec une vingtaine de personnes, à réfléchir sur un seul projet qui nous paraissait changer le monde. Nous dessinions beaucoup; nous échafaudions des théories, nous élaborions des méthodes de compositions géométriques qui me sont aujourd'hui très précieuses. Au bout du compte, nous construisions assez peu." (Bofill, 1989:38).

Anna Bofill Levi, arquitecta e música, irmã de Ricardo, integra também o Taller em 1962 e transporta para o debate, de modo intuitivo nos primeiros tempos, as preocupações com o quotidiano das famílias e, em especial, com o das relações de género, nomeadamente a situação de subordinação e de sobretrabalho das mulheres nos agregados domésticos.

No plano da arquitectura, os Bofill e os seus companheiros partilharam precocemente as visões urbanas marxistas (muito influenciados por Henri Lefebvre), acrescentando-lhes alguns traços da pós-modernidade, como, por exemplo, a regeneração de espaços urbanos obsoletos. Materializaram os seus primeiros projectos, durante os anos 60, no litoral de Alicante, em La Manzanera, onde deixaram edifícios emblemáticos como Plexus e Xanadu. Na Catalunha, foram também construídos dois edifícios simbólicos (até no nome) nos anos 60: El Castell de Kafka, em Sitges, e o Barrio Gaudi, em Réus (Bofill Levi, 2009).

Inspirados nas correntes de pensamento mega-estrutural dos anos 60 (que tem como um dos seus mais ilustrativos exemplos o bairro residencial Habitat, projectado por Moshe Safdie para a Expo67 de Montreal), defendiam uma edificação modular num espaço tridimensional (Bofill, 1989; Banyuls i Pérez, 2002; Bofill Levi, 2009). A esta perspectiva, muito geométrica, associavam-se várias reinterpretações das utopias urbanas do século XIX, em especial, a Cidade Jardim. "La Manzanera, planteada como una urbanización turista, creemos que hemos de concebirla como jardín urbanizado (...) 
conservando su carácter en un nuevo paisaje construido, que esté profundamente integrada en los alrededores e idiosincràsia del país. Por todos estos motivos, nosotros intentaremos conservar sus muros de piedra, sus bancales, su vegetación, su naturaleza." (Emilio Bofill, 1968, cit. por Antoni Banyuls i Pérez, 2002: 140).

Ainda no campo meramente arquitectónico, as primeiras intervenções dos Bofill revelam algumas preocupações sociais e políticas bastante nítidas, tais como 'aliviar' a densidade de ocupação através da utilização do espaço tridimensional ${ }^{4}$, possibilitar a circulação horizontal e vertical, centralizar a infraestrutura e os serviços nos espaços residenciais, construir, com elementos pré-fabricados, 'células' (unidades residenciais) que pudessem vir a agrupar-se para constituírem unidades maiores. Nestas preocupações, está subjacente a intenção de reduzir o preço da construção, usando pouco terreno e recorrendo à produção industrial (módulos pré-fabricados), bem como promover a interacção dos habitantes. Está também presente um objectivo mais inovador e audaz que Antoni Banyuls i Pérez (2002:153) refere como "estruturas tridimensionais, tecnológicas e futuristas com capacidade para absorver procuras e transformações sociais imprevisíveis".

Esta ideia, expressa através da arquitectura, inscreve-se no Regionalismo Crítico, ou seja, na necessidade de contextualizar a arquitectura adequando-a aos lugares e às culturas. Este termo parece adaptar-se especialmente bem ao ambiente político e social da Catalunha no final dos anos 60, onde a oposição ao Franquismo e o nacionalismo catalão se conjugavam numa associação particular, por vezes bastante complexa.

“Ces ouvriers, dont j'admirais l'agilité quand je les voyais progresser, les épaules chargées de briques, sur les échafaudages suspendus dans le vide, me parlaient aussi de la guerre perdue. Dans les cafés, après le travail, ils me racontaient les défaites de l'armée républicaine. Une autre initiation." (Bofill 1989: 17).

A perspectiva do Regionalismo Crítico é muito clara nas concepções que os Bofill e o Taller tinham sobre o papel da arquitectura na sociedade. «Savoir regarder, décrypter les comportements et les mouvements spontanés d'une population, et, au-delà, percevoir les besoins de changement qu'elle peut laisser, inconsciemment, transparaitre. Il faut savoir repérer ces manques pour apporter, soi-même sa propre contribution.» (Bofill, 1989: 15).

4 A maioria dos projectos arquitectónicos repetem um plano em altura. Não são, na realidade, tridimensionais. 


\section{Concretização da utopia}

Em 1970, o 'Taller de Arquitectura' começa a desenvolver dois projectos muito ambiciosos, não só pela sua dimensão mas, sobretudo, pela sua localização Trata-se da Ciudad en el Espacio, em Madrid - Moratalaz e o Walden-7, em Barcelona - Sant Just Desvern. O primeiro projecto é interrompido no início da construção, por imposição da administração local franquista que entende este projecto como uma obra com intenções subversivas (Bofill Levi, 2009: 32). O segundo realizou-se e constitui actualmente um caso particularmente interessante de uma utopia que se concretizou.

O Walden-7 homenageia duas obras literárias. Em 1854, Henry David Thoreau publicou Walden; or, Life in the Woods, obra que enaltece a autonomia individual, a descoberta, a relação entre o ambiente e as pessoas, a experimentação social, tecendo uma crítica intensa à sociedade industrial. Inspirado na obra de Thoreau, em 1948, B. F. Skinner publica Walden 2, uma obra de psicologia baseada numa comunidade experimental onde se promove a felicidade e a criatividade, incentivando o espírito crítico e a experiência no sentido de melhorar sempre as práticas culturais do colectivo. Através desta utopia, Skinner formulou uma crítica forte à América do pós-guerra, onde os atributos do Walden 2 estavam bastante desvalorizados.

Os escritores e filósofos do 'Taller de Arquitectura' encontraram nestas obras a inspiração e os fundamentos para o novo conceito de espaço urbano que queriam desenvolver. Um espaço comunitário e solidário, crítico, criativo e experimental.

José Agustín Goytisolo, poeta, co-fundador do Taller, produziu alguns dos textos fundadores do Walden-7. Fundadores porque são fundamentos conceptuais do projecto e fundadores também porque se encontram inscritos nas caves do edifício em painéis que envolvem os pilares principais. O seguinte poema é um exemplo desses textos:
"Al escoger camino en una encrucijada
Y al avanzar por él,
Quedan atrás los otros mil proyectos
Posibles desde el punto de partida.
Determinista o no,
El único sentido de la historia
Es como el largo viaje en un ferrocarril
A medio construir entre la selva
Que cubre su trazado, impidiendo el retorno"
(J. A. Goytisolo)

Depois da experiência falhada da 'Ciudad en el Espacio' ensaiada em Madrid, o Taller sabe aproveitar uma oportunidade única em Barcelona. O terreno e os edifícios abandonados da fábrica de cimento SANSON, recentemente desactivada, estavam à venda em Sant-Just-Desvern, um município 
contíguo ao de Barcelona, para Oeste. O espaço era atractivo, um universo fantástico, nas palavras de Ricardo Bofill (entrevista em Solé et al., 1995), e menos vigiado que o do centro da metrópole catalã. As regras de construção eram pouco rigorosas e vagas num município suburbano como Sant Just e a censura política era mais leve na Catalunha, onde não convinha ao regime franquista provocar demasiados atritos, especialmente num período de contestação como o que sucedeu a 1968.

Os Bofill conseguem, por via das suas relações familiares, o apoio financeiro do Banco Industrial da Catalunha (BIC, administrado, na altura, por Jordi Pujol, posteriormente presidente da Generalidad entre 1980 e 2003) para comprar o terreno (108 milhões de pesetas, em 1968) e financiar a construção, aceitando que, contrariamente aos seus projectos anteriores, os apartamentos fossem vendidos em propriedade horizontal e não através da constituição de uma sociedade accionista. Para gerir este investimento e a comercialização dos apartamentos, o BIC cria uma empresa específica, a Ceex.3. (Anna Bofill Levi, em entrevista realizada pelas autoras em Fevereiro de 2010, e Ricardo Bofill, em entrevista publicada em Solé et al., 1995).

O envolvimento da equipa do Taller neste projecto é total. Finalmente, vão concretizar uma ideia que incorpora novos conceitos do espaço urbano, explicitados por associações complexas entre sistemas geométricos e relações sociais, novas visões arquitectónicas e novos modos de contestação política.

O Walden-7 é um agregado de 1084 células ou unidades volumétricas cúbicas (fig. 2). Cada unidade tem uma área de $30 \mathrm{~m}^{2}$ e cada apartamento pode ocupar uma única célula (estúdio), 2, 3 ou 4 . O espaço habitacional é aberto e pode ser organizado à medida de cada agregado doméstico e consoante a sua evolução ao longo do ciclo de vida dos seus membros. A construção foi especialmente barata, usando abundantemente pré-fabricados e materiais pouco dispendiosos (Xavier Camprecios «'Walden-7' Innovaciones y funcionalidade en la arquitectura», La Vanguardia Española, 16 Novembro 1975).

No mesmo artigo, Xavier Campreciós comenta que no Walden-7 "se han unido funciones que en la concepción clásica de la vivienda permanecían distanciadas por piezas individuales. Tal es el caso de cocina-comedor, de bañohabitación. Aplicando por el contrario la función «estar», de recogimiento personal, en todas ellas". [...] "Los interiores de las viviendas son, pues, de una absoluta adaptación a las necesidades de la gente, hoy y ahora. En el fondo se trata de romper el fenómeno de la mimetización de clases, mediante el cual una clase social imita la construcción y distribución de las viviendas de una clase - generalmente superior - diferente, sin tener en consideración que los usos y necesidades de ambas pueden alcanzar la mayor disparidad».

Embora os detalhes do projecto e da construção sejam bastante interessantes e comportem dimensões muito inovadoras, interessa-nos salientar aqui, sobretudo, as estratégias socialmente criativas que envolvem o Walden-7 desde a sua origem até à actualidade. Destacamos a seguir um conjunto de ideias que configuram o carácter socialmente inovador deste projecto. 


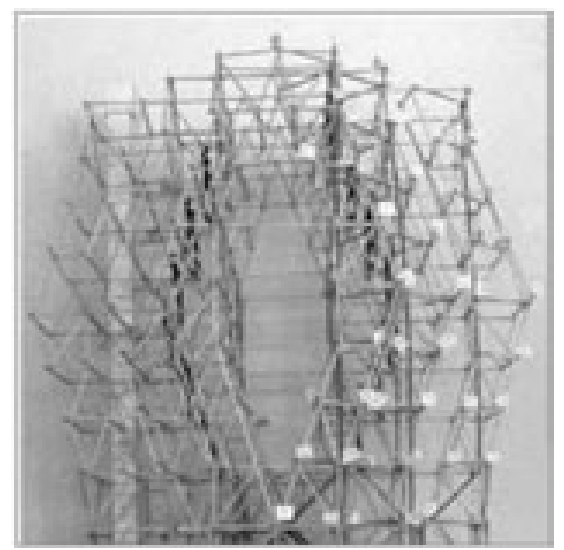

Fig. 2 - Geometria do Walden-7.

Fig. 2 - Geometry of Walden-7.

\section{A inspiração mediterrânea do Walden-7}

“J'ai traversé alors la Méditerranée. J'ai découvert, dans la vallée du Dra, au Maroc, des villages faits de cubes empilés, construits au jour le jour, au rythme de l'expansion des familles et pourtant mystérieusement ordonnés. Tout autour du désert." (Bofill, 1989:13)

A cidade orgânica - que permaneceu no Sul do Mediterrâneo e não resistiu às pressões do mercado no Norte - é o modelo que os Bofill transportam para os seus primeiros projectos e especialmente para o Walden-7. O espaço urbano vai crescendo harmoniosa e equilibradamente à medida que os habitantes vão tendo diferentes necessidades e modos de vida. As kasbahs do Magreb estão claramente representadas no Walden-7 com a sua sobreposição de planos diversos, cores e labirintos. Outro aspecto interessante transposto da cidade orgânica para o Walden-7 é o 'vis-a-vis', ou seja, as janelas viradas umas para as outras, o que propicia o diálogo e a interacção dos vizinhos.

Apesar desta inspiração ancorada na história dos povos mediterrânicos, o projecto Walden-7 aliou a tradição a novas técnicas de construção que permitiram ampliar as vantagens da kasbah evitando algumas das suas desvantagens.

\section{A monumentalidade do Walden-7}

O universo mágico da fábrica de cimento SANSON reflectiu-se muito no Walden-7. É, na verdade, um projecto muito precoce de regeneração de um espaço industrial abandonado. Os Bofill tinham visitado, nos anos 60, os primeiros projectos do 'urban renewal' moderno nos EUA, em especial na Califórnia. A ideia não se tinha ainda difundido na Europa, onde só a partir dos anos 
80 é que a reestruturação económica e a desindustrialização se declaram como um desafio à urbanização, não só pela necessidade de regenerar (social e ambientalmente) os espaços abandonados pela indústria, mas também pela forte dimensão simbólica dessas áreas e pela inspiração que transmitem aos projectistas da cidade (Roberts e Sykes, 2000). No contexto da regeneração urbana, os flagships assumem um papel crucial, atribuindo grandiosidade, visibilidade e mesmo monumentalidade aos espaços, o que facilita muito a sua apropriação e identidade. $\mathrm{Na}$ maioria das situações, a importância dos flagships é vista sobretudo em termos de mercado, atracção de investimentos e de empresas, mas nalguns casos associa-se também à integração e identidade das comunidades urbanas (Smyth, 1993).

Talvez não tenha sido intencionalmente que o Taller desenvolveu um projecto de regeneração urbana. A aquisição dos terrenos em Sant Just parece ter sido mais ditada pelo acaso e pela possibilidade de concretizar ideias alternativas e subversivas (na óptica dos poderes dominantes) do que pela intenção de regenerar um espaço desindustrializado. De qualquer modo, o Walden foi concebido como um flagship, como um 'monumento ao subúrbio' (Bofill, 1989 ). A fábrica

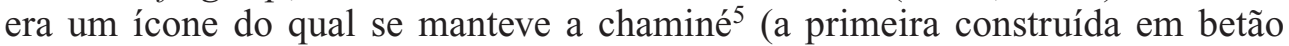
na Europa, 1900). Produziu-se, contudo, um outro ícone semelhante a um castelo visível de longe, uma ilha com o seu farol, onde chegamos, ou um navio com um mastro, onde partimos, consoante as interpretações, mas cuja dimensão o torna visível em grande parte da metrópole catalã.

\section{A comunidade Walden-7}

O projecto Walden-7 foi concebido como habitação social, no modelo 'casas de renda limitada' ${ }^{6}$. Os ideais que veiculava associavam-se a esse tipo de população-alvo. Contudo, o carácter alternativo do projecto e o envolvimento dos membros do Taller na sua execução, fizeram com que a maioria dos primeiros residentes pertencesse à rede social dos Bofill (Anna Bofill Levi, entrevista 5 Fevereiro 2010). Eram sobretudo intelectuais e artistas, pessoas que por convicções políticas e ideológicas escolheram viver num contexto urbano pouco convencional.

«En 1975 empezaron a llegar los primeros inquilinos al Walden 7. "Aquí vinieron a vivir los esnobs modernos de la época, porque parecía una edificio hecho a su medida en la época de las comunas", recuerda Antoni Ardèvol, presidente de

5 Segundo informação de Anna Bofill Levi (entrevista, 5 Fevereiro 2010), a primeira chaminé construída em betão na Europa, em 1900, e, por isso, a mais alta nessa época.

6 As 'casas de renda limitada' foram um instrumento da política de habitação franquista, introduzido em 1954, quando o estado espanhol reconheceu a existência de um enorme défice de oferta de habitação condigna. Permitia apoios directos e indirectos, nomeadamente isenções e bonificações fiscais, bem como facilidades no acesso ao crédito hipotecário (Fernández Carbajal, 2003). 
la comunidad de propietarios. [...] Este edificio sale en todas las enciclopedias arquitectónicas del mundo porque es una concepción nueva de vida. (Carles Mestres «El "monumento al suburbio" de Bofill necesita reformas urgentes», La Vanguardia 6 Abril 1993).

Anna e Ricardo Bofill admitem que o projecto do Walden-7 pretendeu acolher vidas alternativas, anti-convencionais. "Une existence qui exalterait l'individu libéré du couple traditionnel, mais qui lui laisserait, aussi, la possibilité de vivre à trois, à quatre, en communauté." (Bofill, 1989: 37). Esta intenção traduziu-se não só na concepção de um espaço que promove a interacção social, como já referimos, mas também, por exemplo, na existência de vários serviços colectivos que, no projecto inicial, incluíam mesmo uma cozinha e uma lavandaria (que nunca chegaram a funcionar por falta de iniciativa suficiente dos primeiros residentes). Ainda assim, ficou bem expresso no Walden-7 o intuito de favorecer a colectivização do trabalho doméstico e de transformar, por essa via, as relações de género convencionais. Anna Bofill (2005) veio a produzir uma reflexão muito interessante sobre este aspecto específico.

"Deberíamos entender los lugares de la ciudad, desde los domésticos hasta los de relación, de trabajo, etc., como lugares sin jerarquizaciones, ni separaciones, ni segregaciones en donde se desarrolla la vida de cada día en el conjunto de todas las actividades que realizamos. Prescindir de la clásica separación entre los espacios para lo doméstico y los espacios para lo social, que se dan incluso en la vivienda, e intentar domesticar todos los espacios, o hacer domésticos todos los espacios que usamos y vivimos." (Bofill, 2005: 4-5)

A integração da comunidade Walden-7 em Sant Just Desvern não foi difícil. Primeiro, porque se deu num momento de viragem importante, correspondente ao fim do franquismo e início do regime democrático. Em segundo lugar, porque o edifício de localizou na área industrial, relativamente afastada do núcleo residencial mais antigo e, por isso, não provocou grandes alterações no tecido urbano já consolidado, nem mudanças significativas em termos de relações de vizinhança Só a partir dos anos 90 é que a expansão urbana acaba por ligar o 'pueblo' ao Walden-7.

\section{Os ciclos do Walden-7: militância, crise e superação}

Pelas razões indicadas no ponto anterior, os primeiros habitantes do Walden7 pertenciam, na sua maioria, a uma mesma rede social, partilhavam ideais e modos de vida, encontrando no Walden-7 o lugar ideal para a concretização das utopias num momento particular da história de Espanha, que foi a transição para a democracia na segunda metade dos anos 70 do séc. XX.

Como todos os períodos de entusiasmo e militância, esta primeira fase da comunidade Walden-7 não durou muito. 
Mas é preciso ir um pouco atrás para compreender as debilidades com que o Walden-7 se deparou a partir de 1980. Com a crise industrial da Catalunha, agravada pela crise mundial dos anos 70, o Banco Industrial da Catalunha (integrado entretanto no grupo Banca Catalã) entrou em crise, arrastando a Ceex-3. Os pagamentos à empresa Dragados y Construcciones, SA começaram a falhar e a construtora retirou-se antes de finalizado o edifício, sendo substituída por empresas de menor dimensão e com menos qualificações (Enric Canals "Un edificio diseñado por Bofill en 1975, com problemas de desprendimientos", El Pais 21/08/1980). Esta mudança fez com que o revestimento exterior do edifício e outros trabalhos tenham sido realizados deficientemente. Mas, a crise da Ceex-3 levou também a que a maioria dos residentes tenham pago apenas a entrada e não tenham efectuado mais pagamentos, justificando, em parte, esse procedimento com as deficiências que as suas casas começavam a revelar.

De facto, ao fim de poucos anos, os residentes começaram a ver fendas nas paredes, infiltrações nos últimos pisos e a queda sucessiva dos ladrilhos cerâmicos do revestimento exterior. Entretanto, a Ceex-3, em situação financeira cada vez mais débil, pediu a declaração do estado de ruína para o Walden-7, o que levaria à sua demolição sem direito a indemnizações aos residentes, dado que tinham já passado os 10 anos de garantia do edifício. Segundo a lei vigente na Catalunha nesse período, para um edifício ser declarado em ruína era necessário que o valor das obras de reabilitação fosse superior a $50 \%$ do valor do edifício. Contudo, segundo as autoridades urbanas, o Walden-7 valia, em 1985, 1200 milhões de pesetas e as obras estavam estimadas em 389 milhões, o que justificou que a solicitação da Ceex-3 não fosse aceite ("El Ayuntamiento de Sant Just Desvern exige a la constructora que repare el edificio Walden", La Vanguardia, 30 Outubro 1986). Em 1989, a situação legal fica resolvida com a venda simbólica do Walden-7 ao Ayuntamiento de Sant Just Desvern (Carles Mestres e Xavier Arjalaguer "Una Inmobiliaria regala el edificio Walden7 a Sant Just Desvern para frenar su deterioro", La Vanguardia, 15 Junho 1989).

A crise do Walden-7 não foi apenas a da construção. Num novo contexto de tolerância e mudança rápida dos valores e comportamentos sociais associados ao regime democrático, muitos dos ideais associados à comunidade Walden-7 tornaram-se uma realidade por todo o lado. "La Gauche divine s'est dissoute dans la Barcelone de la transition démocratique puis dans celle du socialisme pragmatique" (Bourret, 1999: 31).

Durante a crise do Walden-7 muitos dos seus primeiros habitantes venderam ou alugaram, de facto, os seus apartamentos e o edifício passou a acolher uma população socialmente diferente da inicial, mas aparentemente também anticonvencional, agora já não tanto por motivos político-ideológicos mas sobretudo pelos modos de vida que seguia.

Apesar das contrariedades e de alguma mudança no perfil sócio-cultural dos residentes, a comunidade Walden-7 conseguiu resistir à crise e superá-la. Pela resistência que demonstrou ao longo dos anos mais difíceis mas também 
porque, a partir de 1989, passou a ter o apoio das autoridades públicas urbanas - Ayuntamiento e Generalidad - que entenderam finalmente o Walden-7 como um marco e uma referência da história urbana recente de Barcelona a valorizar.

Em 1989, juntamente com o Walden-7, o Ayuntamiento compra um terreno de $20700 \mathrm{~m}^{2}$ no mesmo quarteirão, para o qual elabora um Plano Especial que permite a recuperação do Walden-7 e a construção de mais de 200 apartamentos, assim como uma zona de serviços e equipamentos. A reabilitação será feita com recurso às hipotecas pendentes dos residentes devedores à Ceex-3, aos apoios financeiros concedidos pela Generalitat e pela venda dos espaços não ocupados, isto é 80 apartamentos e 20 lugares de estacionamento. (Carles Mestres e Xavier Arjalaguer "Una Inmobiliaria regala el edificio Walden7 a Sant Just Desvern para frenar su deterioro", La Vanguardia 15 Junho 1989 e Carles Mestres "La reforma del Walden-7 de Sant Just costará 900 millones de pesetas" La Vanguardia 18 Setembro 1990). O Plano Especial - dos arquitectos Xavier Montsalvatge y Xavier Llistosella - é aprovado em 1992, destinando 67\% do quarteirão a espaços verdes, arruamentos, equipamentos e estacionamento e $33 \%$ a usos privados, incluindo habitação, escritórios e comércio (Carles Mestres "Viviendas, oficinas y. zonas de recreo rodearán al polémico edificio Walden-7", La Vanguardia 7 Abril 1992).

A recuperação - que acabou por custar 705 milhões de pesetas - ficou concluída em 1995 e foi festejada com um grande espectáculo de 'Els Comediants (uma das companhias mais prestigiadas do mundo pela espectacularidade das suas montagens) e com a presença de membros do Governo catalão. $\mathrm{Ou}$ seja, o Walden-7 tinha acabado de ser incluído nos flagships de Barcelona. O próprio Ricardo Bofill, que tinha abandonado a sua utopia, aproximou-se de novo. "Los vecinos están tramando un acuerdo con Bofill: ellos se olvidan de pedirle cuentas por la degradación que ha sufrido el edificio y a cambio el arquitecto les aportará cierta cantidad de dinero y hará "campaña a favor" del Walden 7. De hecho, Bofill ya ha firmado varios artículos de prensa (uno de ellos en "La Vanguardia") en los que se reconcilia con el edificio del que años atrás había renegado" (David Miquel, «El polémico Walden 7 limpia su cara y deja atrás su imagen de frágil castillo de naipes», La Vanguardia, 11 Março 1995).

Com esta intervenção, os apartamentos do Walden-7 aumentaram significativamente de preço. As casas que estavam vagas, ou que por qualquer razão iam sendo desocupadas, passaram a ter uma procura significativa, o que, a médio prazo, pode provocar mudanças no perfil social dos residentes Contudo, o fenómeno de gentrificação, tão frequente nestas situações, não parece ter, por enquanto, grande expressão. Assim, convivem ainda actualmente no Walden-7 alguns dos que fundaram a comunidade militante de vizinhos e todos aqueles que foram chegando durante a crise e nos anos mais recentes. Em comum, parecem partilhar, no essencial, os valores que guiaram o Walden-7 desde a sua concepção. 


\section{O PRESENTE NO WALDEN-7}

Actualmente, o Walden-7 alberga uma comunidade de cerca de 1000 residentes, distribuídos por 442 apartamentos. A Junta da Comunidade de Proprietários do Walden-7 gere um orçamento anual de cerca de 500000 dos quais $0,7 \%$ se destinam a acções de solidariedade com países do $3^{\circ}$ Mundo.

Para além de alguns serviços que se mantêm no edifício - farmácia, cafetaria, cabeleireiro - a Junta, através da Comissão de Cultura, organiza 5 grandes eventos culturais em parceria com o Ayuntamiento: visita dels Reis Mags (noite de 5 de Janeiro) às crianças do Walden-7; festa de les Lletres, Sant Jordi (sexta-feira à noite antes de 23 de Abril) - versão "waldenita" da Festa do Livro e da Rosa, incluindo leituras em diferentes idiomas e uma taça de champanhe para todos; cinema catalão ao ar livre (uma noite de Julho); La Xocolatada (uma tarde de Outubro) - troca de brinquedos entre crianças vizinhas, desincentivando o consumismo, com uma chávena de chocolate quente para todos, grandes e pequenos, no pátio interior do Walden-7; noite de artes cénicas, em que se dão a conhecer os artistas (música, pintura, fotografia, etc.) que vivem no Walden-7, ou em Sant Just Desvern, incluindo representações e exposições num mesmo espaço.

Um inquérito realizado aos residentes do Walden-7 permite-nos conhecer mais em pormenor esta comunidade. $\mathrm{O}$ questionário, enviado e respondido por via electrónica, foi dirigido a 65 residentes (com a solicitação de ser reenviado a outros vizinhos) e obteve 41 respostas. Embora este inquérito assuma apenas um carácter exploratório, os dados obtidos merecem atenção e abrem pistas de discussão interessantes.

- $52 \%$ têm entre 35 e 54 anos, $13 \%$ são mais jovens e $35 \%$ são mais velhos.

- $74 \%$ nasceram na Catalunha, $16 \%$ noutra Comunidade espanhola e $10 \%$ fora de Espanha.

- $67 \%$ têm ensino superior.

- $15 \%$ vivem sozinhos e $10 \%$ em famílias monoparentais; $13 \%$ vivem com um(a) parceiro(a) do mesmo sexo.

- Como actividades de lazer, privilegiam as viagens (68\%) e a leitura $(65 \%)$.

A maioria destas pessoas vive no Walden-7 há mais de 16 anos (68\%). Antes viviam em Barcelona-cidade (47\%) ou já em Sant Just Desvern (17\%). Só 3\% viviam em Espanha fora da Catalunha e 14\% viviam noutro país.

$\mathrm{Na}$ maioria dos casos vieram viver para o Walden-7 porque a família veio, ou porque têm um(a) parceiro(a) que já vivia aí. Contudo, são bastante referidas as características do lugar como razões para a escolha, nomeadamente a beleza, a proposta arquitectónica e social, a privacidade, o conceito do edifício, a sensação de amplitude, a localização geográfica, a filosofia de vida que proporciona, a 'diferença' ou os serviços que disponibiliza. 
Numa escala de 1 a 6 , classificam com 5.4 'o gosto de viver no Walden-7'. Valorizam sobretudo as características do apartamento (59\%), a proximidade dos amigos (47\%) e as relações com os vizinhos (40\%). Como pontos negativos, apontam a falta de luminosidade dos apartamentos que estão virados para o interior do edifício, o funcionamento de alguns serviços e equipamentos e algum conflito entre vizinhos.

Não é muito elevado o nível de participação nos eventos colectivos, obtendo uma pontuação de 3.7 em 6. Os eventos em que mais participam são a Festa das Letras (Sant Jordi) e a Noite de Artes Cénicas. Para além dos eventos colectivos, que já se realizam, sugerem a organização de concertos.

A gestão do Walden-7 merece uma classificação média de 4.0 em 6. Alguns apontam falta de profissionalismo, mas na maioria dos casos, as críticas focam aspectos muito concretos como a recolha de lixo, o controle do ruído ou as reparações eléctricas.

De um conjunto de definições associadas ao Walden-7, as que reuniram maior acordo foram: um espaço único (5.2 em 6); uma comunidade (4.4); um 'pueblo-ciudad' (4,2); um monumento (4.2); um espaço de tolerância (4.0). Os adjectivos mais associados ao Walden-7 são: original/único, diferente; especial; amigável/solidário; surpreendente; grande/monumental; atrevido, labiríntico.

A possibilidade de estabelecer laços fortes com os vizinhos e preservar, ao mesmo tempo, a privacidade e intimidade é um dos aspectos que mais se salienta no modo como os residentes pensam o Walden-7.

"El Walden no es perfecto, però comparado con los otros edificios que conozco me parece un gran acierto. Me cuesta explicar a la gente que significa para mi el edificio, però sé que me gustaría que más gente pudiera disfrutar de un lugar así: bonito, misterioso para los niños, que permite la relación entre los vecinos però que permite también la intimidad." $\left(\mathrm{Lucia}^{7}\right)$

Segundo alguns residentes, o sentido de comunidade vai-se perdendo. Pelo menos, o sentido original. As pessoas continuam a conviver bastante, mas com objectivos muito mais pragmáticos do que aqueles que conduziram os primeiros habitantes. Ainda que admitam que esta mudança reflecte uma transformação social muito mais ampla, indicam um caminho interessante para o refortalecimento dos laços:

"Todavía no hemos entrado en la era de la comunicación digital y actualmente este sería un factor de unión de la comunidad que facilitaría la comunicación y participación favoreciendo la recuperación del espíritu Waldenita. Recae sobre muy pocos avanzar (la participación de los vecinos se limita siempre al mismo grupo de gente en un tanto por ciento demasiado alto) y hay cosas que hay que dejar a profesionales, invertir y profesionalizar la gestión para favorecer la fluidez en la información y la confianza y participación" (Xavier).

7 Os nomes dos residentes são fictícios, dado que a resposta ao inquérito era anónima. 
Mas, a grande maioria dos depoimentos indica claramente a permanência de um espírito de comunidade. Existe uma identidade e um forte sentimento de pertença.

"El Walden, lo quieres incondicionalmente o lo detestas, no hay término medio. Nosotros que nos identificamos con el Walden no aceptamos las críticas negativas desde fuera (como cuando antes, durante y mucho después de las obras de rehabilitación, los taxistas nos decían: "Ah, al Walden? El edificio con los ladrillos que se caen!" y siempre salía en defensa del Walden con argumentos positivos). Entre nosotros, sí que lo criticamos si hace falta." (Maria)

Este sentimento de pertença, bem expresso nas emoções associadas ao Walden-7 (amor, ódio, surpresa, atrevimento, confiança, etc.) funciona como uma protecção. As pessoas que, por uma razão ou por outra, estão em risco (doença, desemprego ou opções de vida pouco convencionais), encontram frequentemente no Walden-7 um lugar de acolhimento e protecção que decorre de uma intensa rede de relações de vizinhança. As redes informais, mais ou menos efémeras e com geometrias variáveis, são actualmente, com efeito, um dos traços mais fortes das relações de vizinhança no Walden-7.

\section{CONCLUSÃO}

Podemos afirmar que uma comunidade urbana como o Walden-7 é uma inovação social decorrente de várias estratégias sociais criativas ancoradas num determinado contexto social, económico e político.

Em primeiro lugar, a estratégia subjacente ao projecto que deu origem ao Walden-7 baseia-se numa visão de cidade que visa transformar as relações sociais e mesmo "mudar o mundo" (Ricardo Bofill, 1989: 38) através da configuração e organização do espaço urbano e, em particular, das áreas residenciais. O projecto do Walden-7 incluiu soluções que faziam inflectir a ordem estabelecida, por exemplo, no campo das relações familiares e de género. Por outro lado, o Walden-7 foi assumidamente um instrumento de contestação, tanto à Espanha franquista como à cidade funcionalista.

Em segundo lugar, a concretização do projecto dos Bofill é, também ela, uma estratégia de oportunidade. A obra só foi possível por se localizar numa área suburbana, na época menos sujeita à vigilância dos poderes públicos, e por ter o apoio de uma instituição e de uma pessoa - o Banco Industrial da Catalunha e Jordi Pujol - que, como se verificou posteriormente, representavam o poder económico da Catalunha e a sua capacidade política para se confrontar com o governo do estado espanhol.

De formas diversas, o projecto e a obra configuraram o 'espírito do lugar', marcado pela emergência de novas sociabilidades e pela constituição de redes informais de vizinhança que garantem apoio e solidariedade, sobretudo às pessoas que se encontram em situações mais vulneráveis ou em risco de exclusão. 
Nos primeiros tempos, a comunidade de residentes foi um grupo que se constituiu sem dificuldade, um conjunto de pessoas que partilhavam ideais e que tinham uma origem social semelhante. Potencialmente inovadores porque contestavam o regime político em que viviam e porque faziam parte de uma geração que questionava a hierarquia, a autoridade e a dominação. Não foi o Walden-7 que os tornou inovadores, mas proporcionou-lhes as condições para concretizarem algumas das mudanças sociais que preconizavam.

A capacidade de encontrar novas soluções - de gerar outras inovações sociais - foi posta à prova mais tarde, no período em que a deterioração do edifício era cada dia maior e o fim do Walden-7 parecia estar à vista. A superação dessa crise foi, ou não, o resultado de novas estratégias sociais criativas? No essencial, julgamos que não. As respostas cruciais vieram do exterior, das autoridades públicas - Ayuntamiento de Sant Just Desvern e Generalitat da Catalunha - que reconheceram o valor simbólico do Walden-7 e promoveram a sua reabilitação. Isto não significa que a comunidade de residentes não tenha tido qualquer contributo, mas apenas que essa participação não foi decisiva, nem especialmente inovadora. Contudo, o facto de a crise ter sido ultrapassada fortaleceu a comunidade e valorizou o lugar.

Esta leitura do Walden-7 e do seu percurso ao longo de 4 décadas suscita duas questões relevantes no âmbito do debate sobre inovação social.

A primeira liga-se ao papel da adversidade enquanto motor de inovação. O projecto e a construção do Walden-7 parecem ter sido, em grande medida, fruto de várias adversidades transformadas em oportunidades. Pelo contrário, a crise por que passou o edifício, durante uma década a partir de meados dos anos 80, foi uma adversidade que não gerou inovação, mas apenas respostas institucionais. Será interessante desenvolver este debate e reflectir sobre as circunstâncias e contextos em que a adversidade impulsiona a inovação social.

A segunda questão liga-se à temporalidade da inovação social. Durante quanto tempo uma inovação é realmente inovação? Seria expectável que a comunidade actualmente residente no Walden-7 mantivesse a capacidade de inovação social do início dos anos 70, associada ao próprio projecto? Cremos que a resposta é negativa, mas continua em aberto o debate sobre os 'trajectos' da inovação social.

\section{BIBLIOGRAFIA}

André I, Abreu A (2009) Social creativity and post-rural places: the case of Montemor-o-Novo, Portugal. Canadian Journal of Regional Science/Revue Canadienne des Sciences Régionales, XXXII (1): 101-114.

André I, Abreu A (2006) Dimensões e espaços da inovação social. Finisterra - Revista Portuguesa de Geografia, XLI(81): 121-141.

Banyuls i Pérez A (2002) Arquitectura per al turisme: la utopia urbana de Bofill i el Taller de Arquitectura a la Manzanera (1962-1985). Aguaits 19-20: 129-161.

Bofill Levi A (2009) Generation of forms/kunstlerische Formgebung: space to inhabit, time to think/ Raum zum wohnen, Zeit für Reflexion. Art Stock Books Ltd, Stuttgart. 
Bofill Levi A (2005) Vivienda y espacio comunitario. Jornadas Urbanismo y Género. Una visión necesaria para todo el mundo, Barcelona.

Bofill R (1989) Espaces d'une Vie. Ed. Odile Jacob, Paris.

Bourret M (1999) De l'échec urbanistique au sarcasme littéraire: Walden 7 de Ricardo Bofill. IRIS, Montpellier.

Carnelave P (2006) Creativity in the outcomes of conflict. In Deutsh M, Coleman et al. (eds) The hanbook of conflict resolution: theory and practice. Jossey-Bass, San Francisco: 414-454.

Defourny D, Develtere P (1999) the social economy: the worldwide making of a third sector. In Defourny J et al. (eds.) L'économie sociale au Nord et au Sud, Deboeck, Bruxelles.

Esping-Andersen G (1990) The three worlds of welfare capitalism. Polity Press \& Princeton, Princeton University Press, Cambridge.

Fernández Carbajal, A (2003) La política de vivienda en España durante el franquismo. Ciudad y Territorio - Estudios Territoriales, XXXV(138): 639-654.

Gertler M (2004) Creative cities: what are they for, how do they work, and how do we build them? Canadian Policy Research Networks, Ottawa.

Jacobs J, Fincher R (1998) Cities of Difference. Guilford Press, New York.

Klein J-L (2005) Iniciativa local y desarrollo: respuesta social a la globalización neoliberal. EURE, XXXI(094): 25-39.

Klein J-L, Harrison D (eds) (2007) L'innovation sociale - emergence et effets sur la transformation des sociétés. Presses de l'Université du Québec, Québec.

Martinelli et al. (coord.) (2003) Social innovation, governance and community building - singocom - scientific periodic progress report month 18. (http://users.skynet.be/bk368453/singocom/ index2.html) [Acedido em 12/02/2010].

Moulaert F, Ailenei O (2005) Social economy, third sector and solidarity relations: a conceptual synthesis from history to present. Urban Studies, 42 (11): 2037-2053.

Moulaert F, Demuynck H, Nussbaumer J (2004) Urban renaissance: from physical beautification to social empowerment. Lessons from Bruges - Cultural Capital of Europe 2002. City, 8(2): 229-235 .

Moulaert F, MacCallum D, Hillier J, Vicari S (eds) (2009) Social innovation and territorial development. Ashgate, Farnham.

Roberts P, Sykes H (eds) (2000) Urban regeneration: a handbook. Sage Publications, London.

Runco M (2004) Creativity. Annual Review of Psychology, 55: 657-87.

Smyth H (1993) Marketing the city. The role of flagship developments in urban regeneration. Taylor \& Francis, London.

Solé i Ubeda J, Amigó J, Miserachs X (1995) Walden 7 i mig. Ed. L'Ajuntament Sant Just Desvern.

Tremblay D-G, Klein J-L, Fontan J-M (2005) Innovation socioterritoriale et reconversion économique: Le cas de Montréal. Editions L'Harmattan, Paris. 